Jul 1st, 12:00 AM

\title{
Dealing with uncertainty in ecosystem model scenarios: application of singlemodel ensemble approach
}

\author{
Gideon Gal
}

Vardit Makler-Pick

Noam Shachar

Follow this and additional works at: https://scholarsarchive.byu.edu/iemssconference

Gal, Gideon; Makler-Pick, Vardit; and Shachar, Noam, "Dealing with uncertainty in ecosystem model scenarios: application of singlemodel ensemble approach" (2012). International Congress on Environmental Modelling and Software. 21.

https://scholarsarchive.byu.edu/iemssconference/2012/Stream-B/21

This Event is brought to you for free and open access by the Civil and Environmental Engineering at BYU ScholarsArchive. It has been accepted for inclusion in International Congress on Environmental Modelling and Software by an authorized administrator of BYU ScholarsArchive. For more information, please contact scholarsarchive@byu.edu, ellen_amatangelo@byu.edu. 


\title{
Dealing with uncertainty in ecosystem model scenarios: application of single- model ensemble approach
}

\author{
Gideon $\mathrm{Gal}^{\mathrm{a}}$, Vardit Makler-Pick ${ }^{\mathrm{b}}$, and Noam Shachar ${ }^{\mathrm{a}}$ \\ a- Kinneret Limnological Laboratory, Israel Oceanographic and Limnological \\ Research, Migdal, Israel \\ b- Oranim Academic College Kiryat-Tivon, Israel \\ gal@ocean.org.il
}

\begin{abstract}
Complex ecosystem models are often used as a means for gaining insight into ecosystem processes and as a management tool for resource managers. The uncertainty associated with these models present, however, a major stumbling block in their acceptance as a main stream management tool. Even if used, there is often a lack of confidence in the results and predictions due to the uncertainty. In addition, the difficulty in estimating model uncertainty and resulting error associated with simulation outcomes further limits model use. The lake ecosystem model DYRESM-CAEDYM (DYCD) includes hundreds of parameters and processes and inherently incorporates a large degree of uncertainty associated with model results. DYCD has been applied extensively to Lake Kinneret in recent years in various forms including as a means for examining long term management strategies.

In this study, we test the reliability of the model as a management tool, given the large degree of parameter uncertainty. We do so by applying a single-model ensemble approach. Based on a sensitivity analysis (SA) previously conducted on the Lake Kinneret application of the model we introduced parameter uncertainty into the model response to a series of management scenarios. We do so in an attempt to test the underlying assumption that the trends predicted by the model, in response to the scenarios, are consistent across the range of uncertainty. The results of all the simulations, for each scenario, were combined to provide an ensemble of results for a series of state variables. Based on the variation in scenario results we estimated the consequences of parameter uncertainty for lake resource management.
\end{abstract}

Keywords: Single-model ensemble approach; DYRESM-CAEDYM; model uncertainty; management scenarios

\section{INTRODUCTION}

Ecosystem models are often used by resource managers and scientists to predict the response of environmental systems to potential management actions or anthropogenic forcing. The use of ecosystem models, in this context, provides a means for studying the likely response and, hence, relationship between internal and external processes affecting the ecosystem [Gal et al., 2009; Makler-Pick et al., 2011a; Paraprov and Gal, 2012]. The use of ecosystem models can, in turn, lead to improved resource management. The results of complex models, such as lake ecosystem models, often suffer, however, from limitations due to various sources of error and uncertainty such as the initial conditions, input data, model structure, model parameters, validation data, etc. [Beck, 1987]. In such complex models, it is extremely difficult to independently quantify each of these sources of uncertainty and error, let alone their combined effect [Tebaldi et al. 2005]. As a 
consequence, the associated uncertainty and error surrounding the outcome of ecosystem models can limit their use and reliability as a management tool.

One of the issues that often limit applications of ecosystems models as a management tool relates to parameter uncertainty. And indeed, parameter uncertainty is a key issue when dealing with a complex model due to the large number of parameters and the uncertainty as to their true values [Helton et al., 2006]. As a consequence, calibration of complex models, with large numbers of parameters, can be difficult. While for some of the parameters the true values can be empirically established or measured experimentally, typically a large number of parameter values will need to be determined based on best estimates.

Ecosystem models can serve as key management tools because of their ability to define the relationships between management measures and ecosystem response based on model scenario simulations. In order to increase the reliability of the model as a management tool it is important to estimate the degree of uncertainty surrounding those predicted relationships. There are diverse approaches for estimating and quantifying uncertainty of the various model components affecting model outcome [Walker et al., 2003; Helton et al., 2006]. Typically, uncertainty analyses employ probabilistic descriptions of model inputs that derive probability distributions of model outputs and system performance indices (Loucks et al., 2005). Most methods become extremely challenging when applied to complex models that include hundreds of parameters and dozens of state variables (Smith, 2002). We therefore attempt to circumvent this issue by taking a different approach in assessing part of the uncertainty associated with model scenario results.

A multi-model ensemble modeling approach in which a given scenario is simulated on a series of models is popular among the climate change community [IPCC, 2007]. Combining multi-model ensemble can help quantify initial condition, parameter as well as structural uncertainties in the model design [Telbadi et al., 2005]. While the use of the ensemble approach will not provide a unique answer or response (e.g. how much warmer will the lake be in 50 years?) it will increase the reliability of the results [Velazquez et al., 2011]. The use of an ensemble approach requires, however, multiple models. In practice, the existence of multiple models is rarely found for a given lake ecosystem.

In cases, however, where only a single model is available for a given ecosystem, a single-model ensemble approach is required [Palmer et al., 2004]. The application of an ensemble approach using a single model can provide resource managers with an assessment of the reliability of model management scenarios. In this approach, similar to a Monte Carlo (MC) approach, multiple simulations are conducted with the same model, for a given scenario, while parameter values are varied between simulations. As the ensemble approach can be computationally taxing it is important to carefully select the simulations to be conducted. The ensemble of simulations allows determination of a range of results for each scenario. This range of results will reflect the variation in parameter space. It is then possible to establish whether the management scenario outcome is consistent across all simulations regardless of the possible errors in parameter values. A consistent ecosystem response over a large parameter space, in relation to a particular management action (i.e. scenario), will increase model reliability and strengthen the conclusions derived from the model results.

In this paper, we attempt to study the effect of parameter uncertainty in a lake ecosystem model (DYCD) on the analysis of management scenarios using the calibrated model for Lake Kinneret, Israel. Rather than conducting a rigorous UA, we estimate the impact of parameter uncertainty by employing a single-model ensemble approach utilizing methodology applied to the SA conducted previously on the model. The underlying assumption in our work is that consistent ensemble responses by the simulated ecosystem to the management scenarios across the 
wide range of parameter values indicate robust model output. The consistency in the simulated trends provides further support for the use of the model as a reliable management tool.

\section{METHODS}

\subsection{Model and scenarios}

We use the 1-D hydrodynamic-ecological model, DYRESM-CAEDYM, (DYCD) to study a series of management scenarios for Lake Kinneret. DYCD simulates the hydrodynamic and the biogeochemical dynamics for aquatic ecosystems. The hydrodynamic model DYRESM uses a Lagrangian approach for simulation of the hydrodynamics of aquatic ecosystems [Imberger and Patterson, 1981]. Based on inflows, withdrawals, and meteorological conditions, it calculates water level, temperature, salinity and stratification dynamics over time. DYRESM has been applied to lakes of varying types [Trolle et al. 2008; Wallace et al., 2000] including to Lake Kinneret [Gal et al., 2003].

The biogeochemical model CAEDYM dynamically couples with DYRESM to simulate nutrient cycling and various phyto- and zooplankton groups. CAEDYM consists of a series of partial differential equations to simulate time-varying concentrations of biogeochemical variables accounting for processes such as primary production, secondary production, nutrient cycling, oxygen dynamics and sediment-water interactions. The combination of DYRESM and CAEDYM constitutes a lake ecosystem model, DYCD, which has been applied for a number of years to Lake Kinneret [Bruce et al. 2006; Makler-Pick et al. 2011a]. A detailed description of CAEDYM configuration, differential equations and parameterizations as applied to Lake Kinneret along with calibration and validation results are given in $\mathrm{Gal}$ et al. [2009]. Of a total of over 40 possible state variables the current analysis focuses on 7 key biological and chemical variables: TN, TP, $\mathrm{PO}_{4}, \mathrm{NH}_{4}$, $\mathrm{NO}_{3}$, dinoflagellates, and cyanobacteria.

In order to evaluate the effect of the model parameter uncertainty on the outcome of management scenarios, we assess the likely impact of changes in nutrient loading ( $\mathrm{P}$ loading in this study) on the lake ecosystem by conducting a series of scenarios. P loading was changed between $\times 0.1$ and $\times 10$ of the base level $(\times 1)$ determined by actual data collected during the year 2002. This year is considered to represent a typical year. This approach is similar to the approach used by Parparov and Gal [2012] but in this study we do it for a wider range of parameter values as described below.

\subsection{The Study Design}

The study was conducted in two stages. The first stage was aimed at filtering and excluding extreme parameter sets, while in the second stage, the scenario stage, we conducted simulations for a series of phosphorus loading scenarios.

\section{Stage 1}

As the MC approach can be computationally taxing it is important to carefully select the simulations to be conducted. Determining the parameter values to be used in this approach can in itself be challenging. We, therefore, take advantage of an approach employed for the DYCD SA. The use of this previously tested approach provided a means for conducting a manageable number of simulations, while covering the necessary parameter space. Based on the SA designed and applied to DYCD [see Makler-Pick et al., 2011b for details and approach] values for 180 input parameters were generated using a Latin Hypercube Design [LHD, McKay et al., 1979]. Briefly, for each of the 180 parameters a defined range of acceptable values were determined based on our best estimates. In cases where measurements for the parameter were available, the acceptable range was narrow while in other cases we used a wide range of values [see Makler-Pick et al., 
2011b]. In most cases the calibrated parameter value was located at the center of the parameter range used. In many of the cases where no prior information was available for a given parameter, and wide range of values were used, the range often included values that were extreme and known not to be possibly correct but nevertheless were used in order to examine the impact on the sensitivity of the model. Based on the LHD, we divided the unit interval of each parameter into 1288 equal subintervals. One value was randomly selected from each interval and the values were permuted and assigned to the first parameter. This procedure was repeated independently for each of the 180 input parameters considered. The model was then run for each of the 1288 parameter sets for a period of 10 years. The forcing data, or boundary conditions, (meteorology, inflows and outflows) used were based on real data for the year 2002, which were repeated from year to year for the entire simulation period. Thus, aside from differences due to leap years, there was no interannual variation in the forcing data. Daily concentrations for the seven variables of interest were output from the model.

The purpose of this stage was to remove parameter sets that result in extreme results mainly due to excessive high or low parameter values. To do so, we analysed the results of the 1288 simulations in the following way: The daily model output for each of the seven variables selected (see above) were averaged over the upper layer of the water column (depth of 0-10 m). The results for 4 dates representing the four seasons: 1 Jan., 1 Apr., 1 Jul., and 1 Oct. were examined during year 5 and year 10 of the simulations (a total of 8 dates, or set of results). The model results, of the 8 dates, were then combined and sorted according to value. For each variable the $5^{\text {th }}$ and $95^{\text {th }}$ percentiles were determined as a filter for removing parameter sets that gave extreme variable values. As a result, parameter vectors leading to values below the $5^{\text {th }}$ and above the $95^{\text {th }}$ percentiles were excluded from further use in this study.

\section{Stage 2}

A series of simulations was conducted in which the base level of nutrient loading into the lake was varied over a wide range by multiplying the concentration of $\mathrm{PO}_{4}$ in all inflow water. The multiplication factors used were: $\times 0.1, \times 0.2, \times 0.5, \times 1$ (base run), $\times 2, \times 5$, and $\times 10$. Each scenario (multiplication factor) was simulated with the range of parameter sets determined during stage 1 . For each variable and scenario we computed the annual mean, median, minimum, maximum, $25^{\text {th }}$ percentile, and $75^{\text {th }}$ percentile values. We used the calculated values to test the impact of the parameter uncertainty on the outcome of scenario simulations. We did so by comparing the trends of the mean and median values to the results of the ensemble of simulations defined by the $25^{\text {th }}$ and $75^{\text {th }}$ percentiles for each scenario.

\section{RESULTS and DISCUSSION}

\section{Stage 1}

Analysis of the results of the seven state variables for the entire ensemble of simulations representing the 1288 different parameter vectors presented a number of extreme ranges. We analysed results for 4 dates representing the four seasons during the fifth and tenth year of the simulations. The range between the minimum and maximum values covered several orders of magnitude (Table 1). The differences between mean and median values, for example for the dinoflagellates, and cyanobacteria, further highlighted the often extreme values found in some cases. While the TP and TN median, $25^{\text {th }}$ and $75^{\text {th }}$ percentile values did not vary greatly over the period examined, there was large variation in the maximum TP values (Fig. 1).

In order to limit the impact of extreme values in the remaining analysis, we removed the lowest and highest extreme 5\% simulations for each variable. In some cases there was overlap between the parameter vectors leading to the extreme results in the different variables. As a result, a total of 236 parameter sets were removed and were not included in the scenario simulations conducted as part 
of stage 2. Therefore, for each loading scenario, 1052 simulations were conducted resulting in a total of $736410-y r$ simulations.

\section{Stage 2}

The impact of $P$ loading on various output variables can be illustrated by the ensemble of 7364 simulations. The ensemble points to an increase in TP and an increase in the inter-quantile range as $P$ loading increases (Fig. 2A). The changes in the simulated TN were moderate with an increase up to the $\mathrm{x} 2$ multiplication factor. An increase in P loading above that level did not result in an increase in TN, rather a modest decrease at the $\times 10$ level (Fig. 2B). More importantly, for both TP and TN, the mean and median values tracked the range of values limited by the $25^{\text {th }}$ and $75^{\text {th }}$ percentiles. There were, however, differences between the mean values and the $25^{\text {th }}$ and $75^{\text {th }}$ percentiles at the various multiplication levels. There was a $25-33 \%$ and $11-16 \%$ deviation between TN mean values and the $25^{\text {th }}$ and $75^{\text {th }}$ percentiles, respectively, and $18-46 \%$ and $12-21 \%$ between TP mean values and the $25^{\text {th }}$ and $75^{\text {th }}$ percentiles, respectively (Table 2). Nevertheless, in most cases there were strong correlations between the mean values and the $25^{\text {th }}$ and $75^{\text {th }}$ percentiles indicating an overlap in the predicted trends represented by the mean value and the ensemble. The exceptions were due to the lower limits of the algal groups which are set by user defined parameters. This key feature, of the overlap in trends, indicates that even given large uncertainty associated with the parameter values the simulated tendencies driven by the $\mathrm{P}$ loading scenarios are similar. As a result, recommendations provided to the resource managers in respect to TP and TN are on a firm basis in spite of the parameter uncertainty in the model.

Table 1. Summary table of the first stage of the analysis. Results represent model simulations in which 1288 different parameter vectors were used.

\begin{tabular}{|l|l|l|l|l|l|l|}
\hline & Mean & Median & Min & Max & $\begin{array}{l}25^{\text {th }} \\
\text { percentile }\end{array}$ & $\begin{array}{l}75^{\text {th }} \\
\text { percentile }\end{array}$ \\
\hline $\mathrm{TN}\left(\mathrm{mg} \mathrm{N} \mathrm{L}^{-1}\right)$ & 0.54 & 0.53 & 0.009 & 1.82 & 0.42 & 0.64 \\
\hline $\mathrm{TP}\left(\mathrm{mg} \mathrm{P} \mathrm{L}^{-1}\right)$ & 0.02 & 0.02 & $8.9 \mathrm{e}-5$ & 0.13 & 0.02 & 0.03 \\
\hline $\mathrm{PO}_{4}\left(\mathrm{mg} \mathrm{P} \mathrm{L}^{-1}\right)$ & $1.5 \mathrm{e}-4$ & $2.3 \mathrm{e}-5$ & $2.1 \mathrm{e}-9$ & 0.05 & $7.5 \mathrm{e}-6$ & $7.5 \mathrm{e}-5$ \\
\hline $\mathrm{NH} 4\left(\mathrm{mg} \mathrm{N} \mathrm{L}^{-1}\right)$ & $3.3 \mathrm{e}-3$ & $3.5 \mathrm{e}-4$ & $5.6 \mathrm{e}-6$ & 0.48 & $1.5 \mathrm{e}-4$ & $1.5 \mathrm{e}-3$ \\
\hline $\mathrm{NO} 3\left(\mathrm{mg} \mathrm{N} \mathrm{L}^{-1}\right)$ & 0.08 & 0.04 & $3.1 \mathrm{e}-7$ & 1.03 & 0.01 & 0.10 \\
\hline Dinof $\left(\mathrm{mg} \mathrm{C} \mathrm{L}^{-1}\right)$ & 0.05 & $9.2 \mathrm{e}-4$ & 0.006 & 21.3 & 0.007 & 0.03 \\
\hline Cyano $(\%)$ & 0.23 & 0.02 & 0.006 & 19.1 & 0.01 & 0.06 \\
\hline
\end{tabular}

The model simulations indicated a slightly inverse relationship between the $\mathrm{P}$ load and dinoflagellates with biomass declining with an increase in P loading (Fig. 2C). This pattern can be seen both in the median and $75^{\text {th }}$ percentile values. The $25^{\text {th }}$ percentile is limited by the minimum biomass value defined in the model. The mean values, are influenced by a relatively small number of high values and thus are beyond the region delimited by the $75^{\text {th }}$ percentile. This was also the case for the cyanobacteria (Fig. 2D) and other algal groups (not shown) and is a result of some of the extreme parameter values. Nevertheless, the pattern and trend of the mean values were similar to the trend defined by the median values (dinoflagellates only) and the region between the minimum biomass and $75^{\text {th }}$ percentile. 

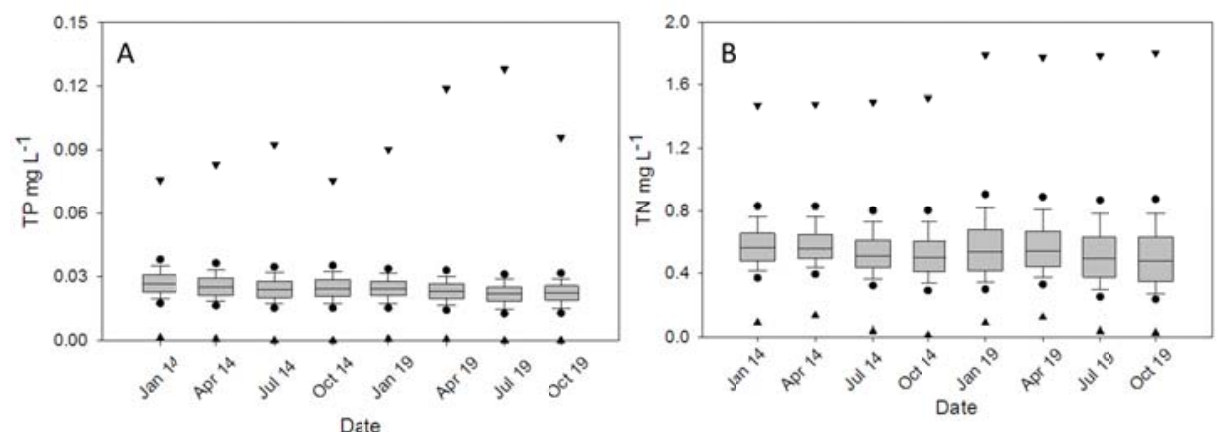

Figure 1. Box plot graphs displaying the inter-quantile range (boxes), minimum and maximum values (triangles), the $5^{\text {th }}$ and $95^{\text {th }}$ percentile (dots), the $10^{\text {th }}$ and $90^{\text {th }}$ percentile (bars) and the median (horizontal line) of 1288 runs for TP (A) and TN

(B), in 1 Jan, 1 Apr., 1 Jul., and 1 Oct of year five and ten of the simulations.
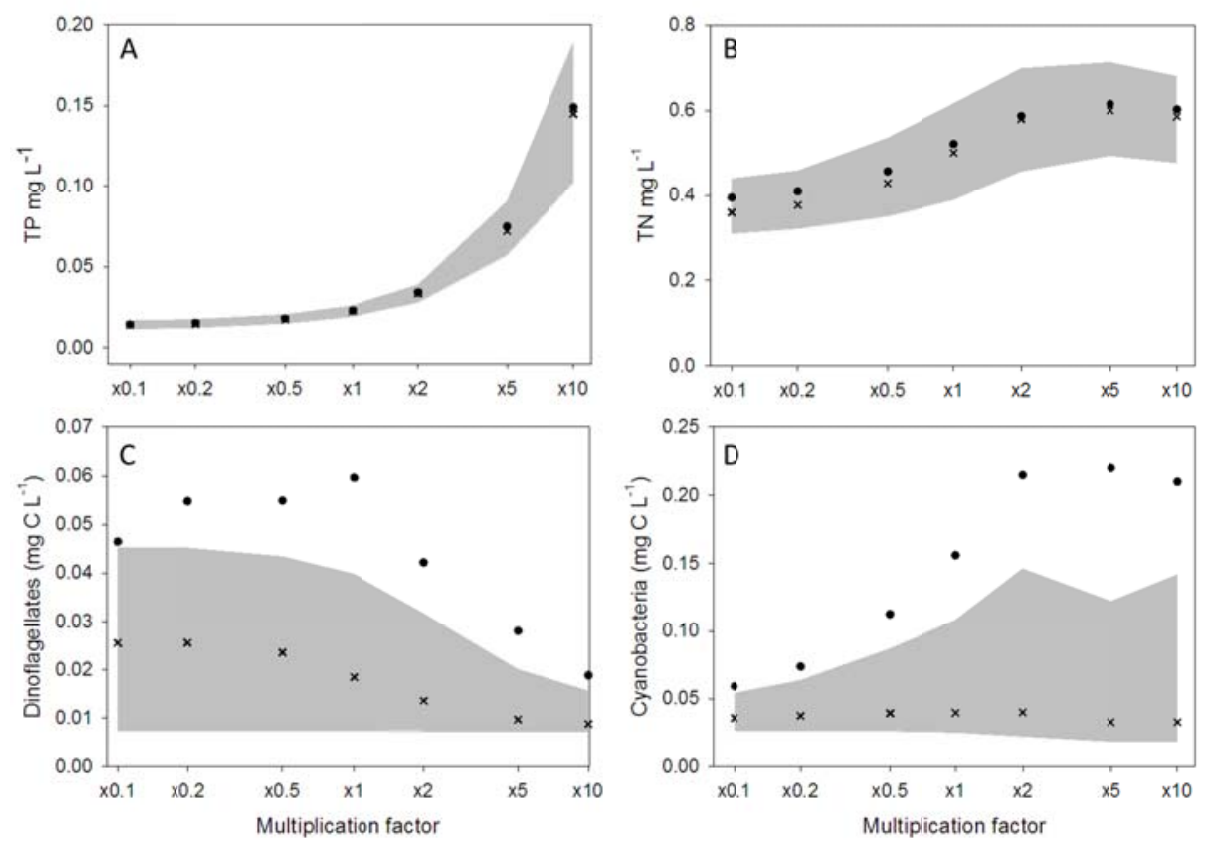

Figure 2. The impact of changes in $P$ loading on mean (solid circle) and median $(x)$ annual values of TP (A), TN (B), dinoflagellates (C) and cyanobacteria (D) as predicted by the entire ensemble of simulations for each scenario. The grey region represents the values between the $25^{\text {th }}$ and $75^{\text {th }}$ percentiles.

The increase in $\mathrm{P}$ loading resulted in an increase in the average cyanobacteria biomass up to $\times 2$ loading. Beyond a doubling of the $P$ load the cyanobacteria biomass tends to be insensitive to the $P$ loading values (Fig. 2D). The increase in $P$ loading resulted in a decrease in the relative contribution of cyanobacteria to total algal biomass, decreasing from an annual mean value of $35 \%$ at a loading factor of $\times 0.1$ to $15 \%$ at the $\times 10$ loading factor (Table 2). More importantly, as with the dinoflagellate biomass, the trend defined by the mean values reflected the trend defined by the $25^{\text {th }}-75^{\text {th }}$ percentile region. The similarity in trends thus lends support to conclusions that can be derived from the scenarios based only on mean values even with the given uncertainty. 
Table 2. Summary table for the correlation between $P$ loading and TN, TP, $\mathrm{PO}_{4}$ $\mathrm{NH}_{4}, \mathrm{NO}_{3}$, dinoflagellates, and cyanobacteria: mean, median, $25^{\text {th }}$ and $75^{\text {th }}$ percentile. The correlation factor between the mean value and the $25^{\text {th }}$ and $75^{\text {th }}$ percentiles are also given.

\begin{tabular}{|c|c|c|c|c|c|c|c|c|c|}
\hline $\begin{array}{l}\text { Multiplication } \\
\text { factor }\end{array}$ & & 0.1 & 0.2 & 0.5 & 1 & 2 & 5 & 10 & Corr \\
\hline \multirow{4}{*}{$\begin{array}{l}\text { TN } \\
\left(\mathrm{mg} \mathrm{N} \mathrm{L}^{-1}\right)\end{array}$} & Mean & 0.39 & 0.41 & 0.46 & 0.52 & 0.59 & 0.62 & 0.60 & \\
\hline & Median & 0.36 & 0.38 & 0.43 & 0.50 & 0.58 & 0.60 & 0.59 & \\
\hline & $\begin{array}{l}\text { 25th } \\
\text { percent. }\end{array}$ & 0.31 & 0.32 & 0.35 & 0.39 & 0.46 & 0.49 & 0.48 & 0.99 \\
\hline & $\begin{array}{l}\text { 75th } \\
\text { percent. }\end{array}$ & 0.44 & 0.46 & 0.53 & 0.62 & 0.70 & 0.71 & 0.68 & 0.99 \\
\hline \multirow{4}{*}{$\begin{array}{l}\text { TP } \\
\left(\mathrm{mg} \mathrm{P} \mathrm{L}{ }^{-1}\right)\end{array}$} & Mean & 0.01 & 0.02 & 0.02 & 0.02 & 0.03 & 0.07 & 0.15 & \\
\hline & Median & 0.01 & 0.01 & 0.02 & 0.02 & 0.03 & 0.07 & 0.14 & \\
\hline & $\begin{array}{l}\text { 25th } \\
\text { percent. }\end{array}$ & 0.01 & 0.01 & 0.02 & 0.02 & 0.03 & 0.06 & 0.10 & 0.99 \\
\hline & $\begin{array}{l}\text { 75th } \\
\text { percent. }\end{array}$ & 0.02 & 0.02 & 0.02 & 0.03 & 0.04 & 0.09 & 0.19 & 0.99 \\
\hline \multirow{4}{*}{$\begin{array}{l}\mathrm{PO}_{4} \\
\left(\mathrm{mg} \mathrm{P} \mathrm{L}^{-1}\right)\end{array}$} & Mean & $8.2 e-5$ & $8.8 e-5$ & $1.0 \mathrm{e}-4$ & $1.3 e-4$ & $1.8 \mathrm{e}-4$ & $4.1 e-4$ & $1.2 \mathrm{e}-3$ & \\
\hline & Median & $6.5 e-5$ & $6.6 e-5$ & $6.4 e-5$ & $6.8 e-5$ & $8.3 e-5$ & $1.7 \mathrm{e}-4$ & $4.5 e-4$ & \\
\hline & $\begin{array}{l}\text { 25th } \\
\text { percent. }\end{array}$ & $3.6 e-5$ & 3.3e-5 & $3.0 e-5$ & $3.0 e-5$ & $3.7 e-5$ & $7.1 e-5$ & $1.7 e-4$ & 0.99 \\
\hline & $\begin{array}{l}75 \text { th } \\
\text { percent. }\end{array}$ & $1.1 \mathrm{e}-4$ & $1.2 \mathrm{e}-4$ & $1.5 e-4$ & $1.6 e-4$ & 2.0E-4 & $4.2 e-4$ & $1.3 e-3$ & 0.99 \\
\hline \multirow{4}{*}{$\begin{array}{l}\mathrm{NH}_{4} \\
\left(\mathrm{mg} \mathrm{N} \mathrm{L}^{-1}\right)\end{array}$} & Mean & $4.6 e-3$ & $4.3 e-3$ & $3.6 e-3$ & $2.9 e-3$ & $2.2 \mathrm{e}-3$ & $1.5 \mathrm{e}-3$ & $1.4 \mathrm{e}-3$ & \\
\hline & Median & $3.2 \mathrm{e}-3$ & $3.1 e-3$ & $2.8 e-3$ & $2.3 e-3$ & $1.7 \mathrm{e}-3$ & $9.9 e-4$ & $7.8 \mathrm{e}-4$ & \\
\hline & $\begin{array}{l}\text { 25th } \\
\text { percent. }\end{array}$ & $2.1 \mathrm{e}-3$ & $2.0 \mathrm{e}-3$ & $1.8 \mathrm{e}-3$ & $1.4 \mathrm{e}-3$ & $9.2 e-4$ & $4.8 e-4$ & $3.1 \mathrm{e}-4$ & 0.99 \\
\hline & $\begin{array}{l}\text { 75th } \\
\text { percent. }\end{array}$ & $5.4 e-3$ & $5.1 e-3$ & $4.3 e-3$ & $3.6 e-3$ & $2.8 \mathrm{e}-3$ & $1.9 \mathrm{e}-3$ & $1.5 e-3$ & 0.99 \\
\hline \multirow{4}{*}{$\begin{array}{l}\mathrm{NO}_{3} \\
\left(\mathrm{mg} \mathrm{N} \mathrm{L}^{-1}\right)\end{array}$} & Mean & 0.14 & 0.13 & 0.10 & 0.07 & 0.04 & 0.01 & $7.5 e-3$ & \\
\hline & Median & 0.09 & 0.09 & 0.07 & 0.05 & 0.02 & $6.8 e-3$ & $4.0 \mathrm{e}-3$ & \\
\hline & $\begin{array}{l}25 \text { th } \\
\text { percent. }\end{array}$ & 0.07 & 0.06 & 0.05 & 0.03 & $9.2 \mathrm{e}-3$ & $3.3 e-3$ & $2.0 \mathrm{e}-3$ & 0.99 \\
\hline & $\begin{array}{l}75 \text { th } \\
\text { percent. }\end{array}$ & 0.15 & 0.14 & 0.12 & 0.09 & 0.05 & 0.02 & $8.3 e-3$ & 0.99 \\
\hline \multirow{4}{*}{$\begin{array}{l}\text { Dinof. } \\
\left(m g C L^{-1}\right)\end{array}$} & Mean & 0.05 & 0.05 & 0.05 & 0.06 & 0.04 & 0.03 & 0.02 & \\
\hline & Median & 0.03 & 0.03 & 0.02 & 0.02 & 0.01 & $9.7 e-3$ & $8.7 e-3$ & \\
\hline & $\begin{array}{l}25 \text { th } \\
\text { percent. }\end{array}$ & 7.3e-3 & 7.3e-3 & $7.3 e-3$ & $7.2 \mathrm{e}-3$ & $7.2 \mathrm{e}-3$ & $7.2 \mathrm{e}-3$ & $7.2 \mathrm{e}-3$ & 0.48 \\
\hline & $\begin{array}{l}75 \text { th } \\
\text { percent. }\end{array}$ & 0.05 & 0.05 & 0.04 & 0.04 & 0.03 & 0.02 & 0.02 & 0.84 \\
\hline \multirow{4}{*}{$\begin{array}{l}\text { Cyano. } \\
\left(\mathrm{mg} \mathrm{C} \mathrm{L}^{-1}\right)\end{array}$} & Mean & 0.06 & 0.07 & 0.11 & 0.21 & 0.22 & 0.22 & 0.21 & \\
\hline & Median & 0.04 & 0.04 & 0.04 & 0.04 & 0.04 & 0.03 & 0.03 & \\
\hline & $\begin{array}{l}25 \text { th } \\
\text { percent. }\end{array}$ & 0.03 & 0.03 & 0.03 & 0.03 & 0.02 & 0.02 & 0.02 & -0.49 \\
\hline & $\begin{array}{l}\text { 75th } \\
\text { percent. }\end{array}$ & 0.05 & 0.06 & 0.09 & 0.11 & 0.15 & 0.12 & 0.14 & 0.85 \\
\hline \multirow{4}{*}{$\begin{array}{l}\text { Cyano. } \\
\text { (\% of total } \\
\text { algal } \\
\text { biomass) }\end{array}$} & Mean & 34.50 & 32.68 & 29.28 & 26.42 & 23.36 & 17.85 & 15.26 & \\
\hline & Median & 32.82 & 30.12 & 24.33 & 18.96 & 12.72 & 6.29 & 4.61 & \\
\hline & $\begin{array}{l}25 \text { th } \\
\text { percent. }\end{array}$ & 24.04 & 20.47 & 14.04 & 9.49 & 5.88 & 2.90 & 2.00 & 0.96 \\
\hline & $\begin{array}{l}75 \text { th } \\
\text { percent. }\end{array}$ & 43.62 & 42.20 & 40.16 & 36.83 & 33.29 & 22.57 & 17.45 & 0.98 \\
\hline
\end{tabular}

\section{Conclusions and Recommendations}

We conducted a single model ensemble approach in order to evaluate the impact of parameter uncertainty on the outcome of management scenarios applied to an aquatic ecosystem. While an UA is an important component of the modeling processes, it is not always feasible with multi-parameter, complex, ecosystem models. The lack of an UA may lead to reduced confidence in the conclusions that are based on model outcome of management scenarios. In an attempt to address this issue we used a single model ensemble approach to study the impact of parameter uncertainty on model results, and more importantly on the conclusion derived from the management scenarios. The underlying assumption was that a consistent trend associated with an ensemble of results, for the various scenarios, will increase confidence in conclusions drawn from the results. 
The ensemble modelling approach demonstrates, as expected, an impact of $P$ loading on all output variables included in the analyses. A substantial impact is demonstrated on the average value of $\mathrm{TP}, \mathrm{PO}_{4}, \mathrm{NH}_{4}, \mathrm{NO}_{3}$ and Cyanobacteria, $\mathrm{a}$ moderate impact on TN and a weaker impact on Dinoflagellates (Table 2). The resulting trends are similar across all simulations included in the ensemble.

For most of the variables examined, the results of the ensemble of simulations clearly defined a response that was consistent over the wide range of parameter sets explored. In addition, there was a large degree of overlap between the trends defined by the range of results $\left(25-75^{\text {th }}\right.$ percentiles) and the mean values. The consistency in trends and overlap with the mean values indicate that the large degree of parameter uncertainty inherent in the model simulations is not sufficient to discount the patterns observed. These results, thus, support the use of the model for testing management scenarios, such as those examined.

\section{REFERENCES}

Beck, M.B., 1987. Water quality modeling: A review of the analysis of uncertainty. Water Resource Research, 23, 1393-1442.

Bruce, L. C., D. Hamilton, Imberger, J., Gal, G., Gophen, M., Zohary, T. and K.D. Hambright. (2006). A numerical simulation of the role of zooplankton in C, N and P cycling in Lake Kinneret, Israel. Ecological Modeling 193: 412-436.

Gal, G., J. Imberger, Zohary, T, Antenucci, J., Ania, A. and T. Rosenberg. 2003. Simulating the thermal dynamics of Lake Kinneret. Ecological Modeling 162: 69-86.

Gal, G., Hipsey, M.R., Parparov, A., Wagner, U., Makler, V., Zohary, T., 2009. Implementation of ecological modeling as an effective management and investigation tool: Lake Kinneret as a case study. Ecological Modeling, 220, 1697-1718

Helton, J.C., Johnson, J.D., Sallaberry, C., Storlie, C.B., 2006. Survey of samplingbased methods for uncertainty and sensitivity analysis. Reliability Engineering \& System Safety, 91, 1175-1209.

Imberger, J. and J. C. Patterson (1981). A dynamic reservoir simulation modelDYRESM: 5. Transport models for inland and coastal waters. H. B. Fischer. New York, Academic Press: 310-361.

IPCC, 2007. Climate Change 2007: Impacts, Adaptation and Vulnerability. Contribution of Working Group II to the Fourth Assessment Report of the Intergovernmental Panel on Climate Change. Cambridge University Press, Cambridge, United Kingdom and New York, NY, USA.

Loucks, D.P., Van Beek, E., Stedinger, J.R., Dijkman, J.P.M., Villars, M.T., 2005. Water resources systems planning and management: an introduction to methods, models and applications. Paris: UNESCO.

McKay, M.D., Beckman, R.J., Conover, W.J., 1979. A comparison of three methods for selecting values of input variables in the analysis of output from a computer code. Technometrics, 21, 239-245.

Makler-Pick, V., Gal, G., Gorfine, M., Hipsey, M.R., Carmel, Y., 2011b. Sensitivity analysis for complex ecological models - a new approach. Enviornmental and Modeling Software, 26, 124-134

Makler-Pick, V., Gal, G., Shapiro, J., Hipsey, M.R., 2011a. Exploring the role of fish in a lake ecosystem (Lake Kinneret, Israel) by coupling an individual-based fish population model to a dynamic ecosystem model. Canadian Journal of Fisheries and Aquatic Sciences, 68, 1265-1284.

Palmer, T., U. Andersen, et al. (2004). Development of a European multi-model ensemble system for seasonal to inter-annual prediction (DEMETER). Bulletin of the American Meteorological Society 85(6): 853-872.

Parparov, A., Gal, G., 2012. Assessment and implementation of the methodological framework for sustainable management: Lake Kinneret as a case study. Journal of Environmental Management, 101:111-117.

Smith, E., 2002. Uncertainty analysis. Encyclopedia of environmetrics. 
Tebaldi, C., Smith, R.L., Nychka, D., Mearns, L.O., 2005. Quantifying Uncertainty in Projections of Regional Climate Change: A Bayesian Approach to the Analysis of Multimodel Ensembles. Journal of Climate 18, 1524-1540.

Trolle, D., T. B. Jørgensena, et al. 2008. Predicting the effects of reduced external nitrogen loading on the nitrogen dynamics and ecological state of deep Lake Ravn, Denmark, using the DYRESM-CAEDYM model. Limnologica, 38: 220232.

Velázquez, J., Anctil, F., Ramos, M., Perrin, C., 2011. Can a multi-model approach improve hydrological ensemble forecasting? A study on 29 French catchments using 16 hydrological model structures. Advances in Geosciences 29, 33-42.

Walker, W.E., Harremoes, P., Rotmans, J., Van der Sluijs, J., Van Asselt, M., Janssen, P., Von Krauss, M.P.K., 2003. Defining uncertainty: a conceptual basis for uncertainty management in model-based decision support. Integrated Assessment, 4, 5-17.

Wallace, B. B. and D. P. Hamilton (2000). Simulation of water-bloom formation in the cyanobacterium Microcystis aeruginosa. J. Plankton Research, 22(6): 1127-1138. 